\title{
Drug resistance maps to guide intermittent preventive treatment of malaria in African infants
}

\author{
INBARANI NAIDOO ${ }^{1,2}$ and CALLY ROPER ${ }^{1 *}$ \\ ${ }^{1}$ London School of Hygiene and Tropical Medicine, Keppel Street, London, WC1E 7HT, UK \\ ${ }^{2}$ Malaria Research Programme, Medical Research Council, PO Box 70380 Overport 4067, South Africa
}

(Received 12 November 2010; revised 31 March 2011; accepted 18 April 2011; first published online 11 August 2011)

SUMMARY

Intermittent preventive treatment of infants (IPTi) with sulphadoxine pyrimethamine (SP) is recommended as an additional malaria control intervention in high transmission areas of sub-Saharan Africa, provided its protective efficacy is not compromised by SP resistance. A significant obstacle in implementing SP-IPTi, is in establishing the degree of resistance in an area. Since SP monotherapy is discontinued, no contemporary measures of in vivo efficacy can be made, so the World Health Organisation has recommended a cut-off based upon molecular markers, stating that SP-IPTi should not be implemented when the prevalence of the $d h p s 540 \mathrm{E}$ mutation among infections exceeds $50 \%$. We created a geo-referenced database of SP resistance markers in Africa from published literature. By selecting surveys of malaria infected blood samples conducted since 2004 we have mapped the contemporary prevalence of $d h p s 540 \mathrm{E}$. Additional maps are freely available in interactive form at http://www.drugresistancemaps.org/ipti/. Eight countries in East Africa are classified as unsuitable for SP-IPTi when data are considered at a national level. Fourteen countries in Central and West Africa were classified as suitable while seven countries had no available contemporary data to guide policy. There are clear deficiencies in molecular surveillance data coverage. We discuss requirements for ongoing surveillance of SP resistance markers in support of the use of SP-IPTi.

Key words: Antimalarial resistance, maps, $\operatorname{dhps} 540$, intermittent preventive treatment infants.

\section{INTRODUCTION}

IPTi is a promising intervention for reducing malaria and anaemia in young children in malaria endemic countries which can be rolled out within the World Health Organisation's (WHO) Expanded Programme of Immunisation (EPI). A treatment dose of sulphadoxine pyrimethamine (SP) is given at the time of routine vaccination of infants and studies have shown this reduces the incidence of clinical malaria in under-ones by about 30\% (Aponte et al. 2009). The intensification of SP resistance in many parts of Africa has led to concerns that the protective efficacy will be compromised. Since SP is the only drug tested for safety, efficacy and EPI interactions, no alternative drugs are currently available for use in IPTi.

Randomised controlled trials of IP'Ti using sulphadoxine pyrimethamine reported protective efficacies against clinical episodes of malaria ranging from $20 \%$ to $59 \%$ and against anaemia from $10 \%$ to $50 \%$ up to 12 months of age (Schellenberg et al. 2001, 2005; Chandramohan et al. 2005; Macete et al. 2006; Mockenhaupt et al. 2007; Grobusch et al. 2007a,b; Kobbe et al. 2007). The first study of IPTi with SP

* Corresponding author: London School of Hygiene and Tropical Medicine, Keppel Street, London, WC1E 7HT, United Kingdom Tel.: +44 (0) 2079272331 Fax: +44 (0) 207636 8739. Email: cally.roper@1shtm.ac.uk conducted in Ifakara Tanzania during 1999-2000 showed the highest protection against malaria (Schellenberg et al. 2001) but resistance has risen steeply in the following years (Malisa et al. 2010) raising concerns about efficacy. A later trial in an area of exceptionally high SP resistance in Northern Tanzania reported no protective efficacy with SPIP'Ti (Gosling et al. 2009). To examine the relationship between the protective efficacy of SP-IP'Ti and resistance, an analysis of seven SP-IPTi trials was carried out (Griffin et al. 2010). Two measures of SP resistance were used; contemporaneous data from six in vivo efficacy studies using SP and seven molecular studies reporting frequency of $d h f r$ triple and $d h p s$ double mutations within $50 \mathrm{~km}$ of the trial sites. The results suggested that there was a reduction in the protective efficacy of SP-IP'Ti with increasing molecular markers of SP resistance.

$\mathrm{SP}$ resistance occurs via substitutions in the target enzymes dihydrofolate reductase (DHFR) and dihydropteroate synthase (DHPS) coded by point mutations in the dhfr and dhps genes (Cowman et al. 1988; Peterson et al. 1988; Brooks et al. 1994; Triglia and Cowman, 1994). Mutant $d h f r$ alleles are varied and code for a range of tolerance to pyrimethamine from intermediate to high, depending upon the number of mutations present. The triple mutant $d h f r$ allele $(\mathrm{N} 51 \mathrm{I}+\mathrm{C} 59 \mathrm{R}+\mathrm{S} 108 \mathrm{~N})$ is a significant contributor to SP treatment failure. It originated in

Parasitology (2011), 138, 1469-1479. (C) Cambridge University Press 2011. The online version of this article is published within an Open Access environment subject to the conditions of the Creative Commons Attribution-NonCommercial-ShareAlike licence < http:// creativecommons.org/licenses/by-nc-sa/2.5/>. The written permission of Cambridge University Press must be obtained for commercial re-use. 
Asia (Roper et al. 2004) but now has a pan-African distribution dating back to the 1980s (Certain et al. 2008; Maiga et al. 2007).

Sulphadoxine resistant dhps emerged during the 1990s, against this background of high level pyrimethamine resistance. In East Africa the appearance of a $d h p s$ double mutant $\mathrm{A} 437 \mathrm{G}+\mathrm{K} 540 \mathrm{E}$ heralded the arrival of significant SP treatment failures in the region (Naidoo and Roper 2010). The combination of the $d h p s$ double mutant $\mathrm{A} 437 \mathrm{G}+\mathrm{K} 540 \mathrm{E}$ and the $d h f r$ triple mutant were shown to be predictive of early SP treatment failure among malaria patients in Kenya, Uganda and Malawi (Omar et al. 2001; Staedke et al. 2004; Kublin et al. 2002). In West and Central Africa the $d h p s \mathrm{~K} 540 \mathrm{E}$ mutation is rare but the $d h p s \mathrm{~A} 437 \mathrm{G}$ single mutant, combined with triple mutant $d h f r$ was found to be associated with treatment failure in Gabon (Kun et al. 1999), Ghana (Mockenhaupt et al. 2005), the Gambia (Dunyo et al. 2006) and Republic of Congo, Brazzaville (Ndounga et al. 2007). An exception is a study by Marks et al. (2005) in Ghana who reported no association of $\mathrm{A} 437 \mathrm{G}$ with treatment outcome in vivo. Studies done in vitro indicate that the $437 \mathrm{G}$ single mutant confers a lesser degree of drug tolerance than the $\mathrm{A} 437 \mathrm{G}$ and $\mathrm{K} 540 \mathrm{E}$ combined (Brooks et al. 1994; Triglia et al. 1997). Hence it is considered very likely that the consequences for IPTi efficacy are less severe.

The WHO Technical Consultation on Intermittent Preventive Treatment of Infants (WHO, 2009) took account of the differing sensitivity of single and double mutant forms of $d h p s$, noting that $540 \mathrm{E}$ mutations are indicative of high level SP resistance. A prevalence of $50 \%$ of the dhps $540 \mathrm{E}$ mutation is the threshold recommended by WHO to determine whether or not SP-IPTi should be implemented.

In addition to the $d h p s 540 \mathrm{E}$, there are two other mutations which are newly emerging in Africa which, when found in conjunction with the $d h f r$ triple and dhps double mutants, indicate extremely high levels of parasite insensitivity to SP which abrogate SP efficacy for both IPTi and IPTp. These are the $d h f r$ $164 \mathrm{~L}$ mutation and the dhps $581 \mathrm{G}$. Harrington et al. (2009) in a study in Muheza, Tanga region, Tanzania showed that the efficiency of IPTp was largely compromised when pregnant women were infected with parasites expressing the dhps- A437G + K540E+ A581G haplotype. Another recent study at Hale Health Centre, situated $32 \mathrm{~km}$ north of Muheza, reported $55 \%$ prevalence of the same haplotype. The clinical and parasitological cure rate at day 28 was less than $20 \%$ in children aged $6-59$ months treated for clinical malaria with SP (Gesase et al. 2009). The establishment of $\mathrm{A} 437 \mathrm{G}+\mathrm{K} 540 \mathrm{E}+\mathrm{A} 581 \mathrm{G}$ may explain the total lack of protective effect of SP for IPTi in the same area reported by Gosling et al. (2009).

Currently there is a need for standardized information about the $d h p s 540 \mathrm{E}, 581 \mathrm{G}$ and $d h f r 164 \mathrm{~L}$ mutations in African sites where implementation of SP-IPTi is being used or considered for use. The purpose of this review is to summarise current knowledge about the prevalence of the $d h p s 540 \mathrm{E}$ and $581 \mathrm{G}$ and the $d h f r 164 \mathrm{~L}$ markers in a form which is freely accessible and easily understood. We have created maps which are available in interactive form on the worldwide web. They have utility not only in guiding IPTi-SP policy but also in highlighting the gaps in surveillance coverage which need to be addressed.

\section{MATERIALS AND METHODS}

\section{Data collection}

We conducted online literature searches periodically during October 2005 to February 2011 using the Pubmed, African Journal Online and Bioline databases using the search terms 'malaria', ' $d h p s$ ' and ' $d h f r$ ' (Naidoo and Roper, 2010). We included published studies which had been conducted in any malarious African country excluding studies of malaria imported from Africa to non-African countries, animal studies, vaccine trials, prophylaxis studies, methodology studies and in vitro studies of resistance. There were no restrictions applied on the basis of malaria case detection, age, pregnancy status, transmission intensity or molecular method used to detect resistant mutations.

We reviewed the full text of suitable studies and extracted the prevalence of $d h f r$ and $d h p s$ mutations. Data were first written on a proforma containing predesigned data fields, including geo-referenced study site and study year, and subsequently double entered into a data entry system to ensure quality control. We recorded the proportion of infections containing individual $d h f r$ or $d h p s$ point mutations and where possible, the haplotypes of associated point mutations in each gene. The details of studies that were identified and included in our analyses are provided on our website (www.drugresistancemaps.org).

\section{Data analysis}

We analysed the prevalence of $d h p s \mathrm{~K} 540 \mathrm{E}, \mathrm{A} 581 \mathrm{G}$ and $d h f r$ I164L. Graphs showing 540E prevalence through time were generated in Intercooled Stata ver 9.2 with calculated $95 \%$ exact binomial confidence intervals for each study sample. Studies where the year of sampling was not reported were not included in the plots of prevalence through time. We generated graphs to illustrate the prevalence of $d h p s 540 \mathrm{E}$ over a 20 year period, from 1988 to 2009 in six geographical categories. Pearce et al. (2009) identified five geographical regions of mainland Africa consisting of neighbouring countries which share the same $d h p s$ resistance allele lineages. In this study, we added a 
Table 1. Regional sub-division of African countries based on shared $d h p s$ resistance lineages (Pearce et al. 2009) and including islands as a separate category

\begin{tabular}{|c|c|}
\hline Countries & $\begin{array}{l}\text { Regional } \\
\text { category }\end{array}$ \\
\hline $\begin{array}{l}\text { Democratic Republic of Congo (East), } \\
\text { Kenya, Malawi, Mozambique, Rwanda, } \\
\text { South Africa, Swaziland, Tanzania, } \\
\text { Uganda, Zambia, Zimbabwe }\end{array}$ & Southeast \\
\hline Djibouti, Ethiopia, Sudan & Northeast \\
\hline $\begin{array}{l}\text { Benin, Burkina Faso, Ivory Coast, } \\
\text { Equatorial Guinea, Gambia, Ghana, } \\
\text { Guinea, Guinea-Bissau, Liberia, Mali, } \\
\text { Mauritania, Niger, Nigeria, Senegal }\end{array}$ & West \\
\hline $\begin{array}{l}\text { Angola, Democratic Republic of Congo } \\
\text { (West), Gabon, Namibia, Republic of } \\
\text { Congo }\end{array}$ & Southwest \\
\hline Cameroon, Central African Republic & Central \\
\hline Comoros, Madagascar, Sao Tome/Principe & Islands \\
\hline
\end{tabular}

sixth cluster consisting of island populations and these are listed in Table 1.

Vector maps were created in Mapinfo ver 9.0 to illustrate the spatial distribution of $d h f r 164 \mathrm{~L}$ and dhps $581 \mathrm{G}$ prevalence reports. All studies, including those whose study year was not stated were included in these maps. To illustrate the recent prevalence of $540 \mathrm{E}$ we selected only those studies where the samples were collected in 2004 or later and created a composite map showing sites where $540 \mathrm{E}$ was examined and highlighting those where prevalence exceeded the recommended threshold of $50 \%$.

RESULTS

\section{Prevalence of the dhps 540 E mutation}

We identified 119 publications describing 260 unique surveys of $540 \mathrm{E}$ prevalence which fulfilled the inclusion criteria and these are listed in full in the supplementary bibliography S1 (see http://journals. cambridge.org/PAR). The cumulative total number of isolates tested for $540 \mathrm{E}$ was 30224 , of which 10339 $(36 \%)$ tested positive with $540 \mathrm{E}$. The regional distribution of surveys is summarized in Table 2. The most intensively studied area was the Southeast region where 129 surveys were carried out in 83 unique study sites in the 11 Southeast region countries listed in Table 1 . The prevalence of $540 \mathrm{E}$ for successive surveys in each region is plotted with 95\% exact binomial confidence intervals in Fig. 1. The $540 \mathrm{E}$ was common in surveys conducted throughout Southeast and Northeast Africa and its prevalence, which tended to increase over time, was seen to approach $100 \%$ in some areas. In Northeast Africa 27 surveys were conducted in 13 unique study sites in three countries and a prevalence of $100 \% 540 \mathrm{E}$ was reported at one site in 2004 .
In the West, Central, Southwest and Island regions, the prevalence of $540 \mathrm{E}$ never exceeded $50 \%$. In the West we recorded 45 surveys in 35 unique study sites within 14 countries. Among these the majority of surveys reported the $540 \mathrm{E}$ mutation was rare or absent, An exception was a reported prevalence of $23 \%$ in Ibadan, Nigeria. In the five countries of the Southwest region, there were 21 surveys in 16 study sites and the prevalence of $540 \mathrm{E}$ was universally less than $50 \%$. Within the Central region 21 surveys from 11 different study sites all reported $540 \mathrm{E}$ prevalences of under $6 \%$. Similarly the 17 surveys at 12 sites among island populations reported low prevalences of $540 \mathrm{E}$ and the maximum value recorded was $20 \%$ in 2004 in Sao Tome and Principe.

\section{Prevalence of the dhfr 164 L mutation}

All publications in which surveys of $d h f r 164 \mathrm{~L}$ were carried out are listed in the supplementary bibliography S2 (see http://journals.cambridge.org/ PAR). Of 19597 isolates tested for $164 \mathrm{~L}$ in 183 surveys and 114 unique sites, $164 \mathrm{~L}$ was detected in just 130 isolates $(0 \cdot 7 \%)$. The regional distribution of the surveys and mutant positive isolates are shown in Table 2. In Fig. 2 a map illustrating the prevalence of $164 \mathrm{~L}$ shows all the surveys which examined codon 164 in African parasites. Detection rates for the 164L mutation ranged from $0.6 \%$ to $13 \cdot 7 \%$ of isolates tested. The $164 \mathrm{~L}$ mutation was found in the Central African Republic, Comoros, Kenya, Madagascar, Malawi, Rwanda and Uganda but was absent in 21 other countries where surveys were conducted.

\section{Prevalence of the dhps $581 G$ mutation}

All publications in which surveys of $d h p s 581 \mathrm{G}$ were carried out are listed in the supplementary bibliography S3 (see http://journals.cambridge.org/PAR). Of 15331 isolates tested for $581 \mathrm{G}$ in Africa, the mutation occurred in $782(5 \%)$ isolates in 13 countries namely Cameroon, Democratic Republic of Congo, Ethiopia, Ghana, Kenya, Madagascar, Malawi, Mali, Niger, Rwanda, Sudan, Tanzania and Uganda. The $581 \mathrm{G}$ was reported in all the regions except for the Southwest (Table 2). The survey sites and prevalence measurements are recorded in the map in Fig. 3 which shows 14 other countries where surveys were negative. The majority of the surveys recorded $581 \mathrm{G}<50 \%$ although in one study carried out prior to 1997 in Sotuba, Mali the $581 \mathrm{G}$ mutation was reported to be $100 \%$. Recent surveys of the dhps 540 E resistance marker and
their application for SP-IPTi

To focus on the current situation, a subset of recent data was selected using only the surveys of $d h p s 540$ 
Table 2. Prevalence of $d h p s \mathrm{~K} 540 \mathrm{E}$, $d h p s$ A581G and $d h f r$ I164L

\begin{tabular}{|c|c|c|c|c|c|c|c|}
\hline & Southeast & Northeast & Central & West & Southwest & Islands & All Regions \\
\hline \multicolumn{8}{|l|}{ All surveys of K540E } \\
\hline $\begin{array}{l}\text { number of surveys } \\
\text { samples tested for K } 540 \mathrm{E}\end{array}$ & $\begin{array}{r}129 \\
18751\end{array}$ & $\begin{array}{r}27 \\
1537\end{array}$ & $\begin{array}{r}21 \\
2109\end{array}$ & $\begin{array}{r}45 \\
4573\end{array}$ & $\begin{array}{r}21 \\
1076\end{array}$ & 17 & $\begin{array}{r}260 \\
30224\end{array}$ \\
\hline samples tested for $\mathrm{K} 540 \mathrm{E}$ & 18751 & 1537 & $\begin{array}{r}2109 \\
0\end{array}$ & 4573 & 1976 & 1278 & 30224 \\
\hline samples positive for $540 \mathrm{E}$ & 9531 & 609 & 9 & 65 & 95 & 30 & 10339 \\
\hline unique sites surveyed & 83 & 13 & 11 & 35 & 16 & 12 & 170 \\
\hline countries surveyed & 11 & 3 & 2 & 14 & 5 & 3 & \\
\hline \multicolumn{8}{|l|}{ Surveys of K540E since 2004} \\
\hline samples tested for $\mathrm{K} 540 \mathrm{E}$ & 6313 & 280 & 932 & 2392 & 1104 & 1146 & 12167 \\
\hline samples positive for $540 \mathrm{E}$ & 3840 & 276 & 7 & 31 & 64 & 25 & 4243 \\
\hline surveys with $>50 \% 540 \mathrm{E}$ & 34 & 3 & 0 & 0 & 0 & 0 & 37 \\
\hline surveys with $<50 \% 540 \mathrm{E}$ & 8 & 0 & 7 & 11 & 12 & 15 & 53 \\
\hline unique sites surveyed & 32 & 3 & 4 & 10 & 10 & 11 & 70 \\
\hline countries surveyed & 9 & 1 & 2 & 9 & 5 & 3 & \\
\hline \\
\hline $\begin{array}{l}\text { number of surveys } \\
\text { samples tested for A581G }\end{array}$ & 11041 & $\begin{array}{r}12 \\
835\end{array}$ & $\begin{array}{r}9 \\
1220\end{array}$ & $\begin{array}{r}18 \\
889\end{array}$ & $\begin{array}{r}5 \\
275\end{array}$ & $\begin{array}{r}5 \\
1071\end{array}$ & $\begin{array}{r}120 \\
15331\end{array}$ \\
\hline samples positive for $\mathrm{A} 581 \mathrm{G}$ & 690 & 34 & 14 & 43 & 0 & 1 & 782 \\
\hline unique sites surveyed & 45 & 9 & 4 & 14 & 4 & 3 & 79 \\
\hline countries surveyed & 9 & 3 & 2 & 8 & 3 & 3 & \\
\hline \multicolumn{8}{|l|}{ Surveys of I164L } \\
\hline number of surveys & 103 & 13 & 21 & 35 & 5 & 6 & 183 \\
\hline samples tested for $\mathrm{I} 164 \mathrm{~L}$ & 13393 & 1099 & 1513 & 1829 & 395 & 1368 & 19597 \\
\hline samples positive for I164L & 78 & 0 & 1 & 0 & 0 & 51 & 130 \\
\hline unique sites surveyed & 60 & 9 & 15 & 21 & 5 & 4 & 114 \\
\hline countries surveyed & 10 & 3 & 2 & 8 & 3 & 3 & \\
\hline
\end{tabular}

carried out between 2004 and 2009. In all, 90 recent surveys were identified in which 4243 (35\%) of 12167 samples were positive for the $540 \mathrm{E}$ mutation. The regional distribution of these surveys and the proportion which reported prevalences higher than the $50 \%$ cut-off are summarised in Table 2, while their geographical locations are shown in the map in Fig. 4. The Southeast and Northeast regions contained all the survey sites with prevalence of the $540 \mathrm{E}$ mutation $>50 \%$. Prevalence exceeded $50 \%$ in eight countries namely Ethiopia, Kenya, Uganda, Rwanda, Tanzania, Malawi, Zambia and Mozambique. Within this subgroup 40 recent surveys were conducted of which 34 surveys recorded a prevalence of $50 \%$ or more.Exceptions being four studies in Maputo, Mozambique (2004 6\% and 11\%, 2005 16\%. 2006 49\%) and 2 studies in Zambia (Macha 2006 11\%, Mpongwe 2004 46\%). Within individual countries surveys recorded broadly consistent prevalences of the $540 \mathrm{E}$ mutation.

In Ethiopia, three surveys were conducted in Jimma, Dilla and Humera all in 2004 and these reported consistently high $540 \mathrm{E}$ prevalences of $97 \%$, $97 \%$ and $100 \%$ respectively (Gebru-Woldearegai et al. 2005; Schunk et al. 2006; Pearce et al. 2009). The sites cover a wide area-Jimma and Dilla are approximately $220 \mathrm{~km}$ apart and Humera is $900 \mathrm{~km}$ from Dilla. Although there have been no surveys published subsequently, and no surveys detected $\mathrm{dh} f \mathrm{r}$ $164 \mathrm{~L}$ the extreme prevalence of the $540 \mathrm{E}$ in 2004 and early reports of low level $581 \mathrm{G}(<2 \%)$ indicate that
SP-IPTi is likely to be compromised by drug resistance in Ethiopia.

In Kenya, nine surveys were carried out in nine unique sites between 2004 and 2006. The dhps $\mathrm{K} 540 \mathrm{E}$ prevalence was always greater than $50 \%$ and ranged from $74 \%$ in Iguhu, Kakamega District to $99 \%$ in Kombewa, (these sites are about $12 \mathrm{~km}$ apart) (Bonizzoni et al. 2009; Zhong et al. 2008). There are reports of $d h f r 164 \mathrm{~L}$ at prevalences around $3 \%$ in western Kenya suggesting that a very highly SP resistant form might be emerging here (McCollum et al. 2006).

In Uganda, $540 \mathrm{E}$ prevalence has exceeded $50 \%$ since 1999 (Staedke et al. 2004). Surveys conducted during 2002-2004 in six national surveillance sites recorded prevalences of between $80 \%$ (in Mubende) and 98\% (in Tororo) (Francis et al. 2006), and most recently $d h p s 540 \mathrm{E}$ prevalences of $98 \%$ and $100 \%$ were recorded in Rukungiri and Kabale in 2005 (Lynch et al. 2008). Overlaid upon $d h p s 540 \mathrm{E}$ there are emerging foci of $d h p s 581 \mathrm{G}$ (up to $45 \%$ prevalence) and $d h f r 164 \mathrm{~L}$ (up to $14 \%$ prevalence) in southwest Uganda recorded in 2005 (Francis et al. 2006; Lynch et al. 2008) indicating that SP-IPTi will be severely compromised by resistance in this area.

In Rwanda, surveys at Rukara and Mashesha in 2005 and reported prevalences of $97 \%$ and $84 \% 540 \mathrm{E}$ respectively (Karema et al. 2010). The same surveys revealed emergence of the $d h f r 164 \mathrm{~L}(12 \%)$ and $d h p s$ $581 \mathrm{G}(61 \%)$ at Rukara which is approximately $120 \mathrm{~km}$ from the highly resistant populations 


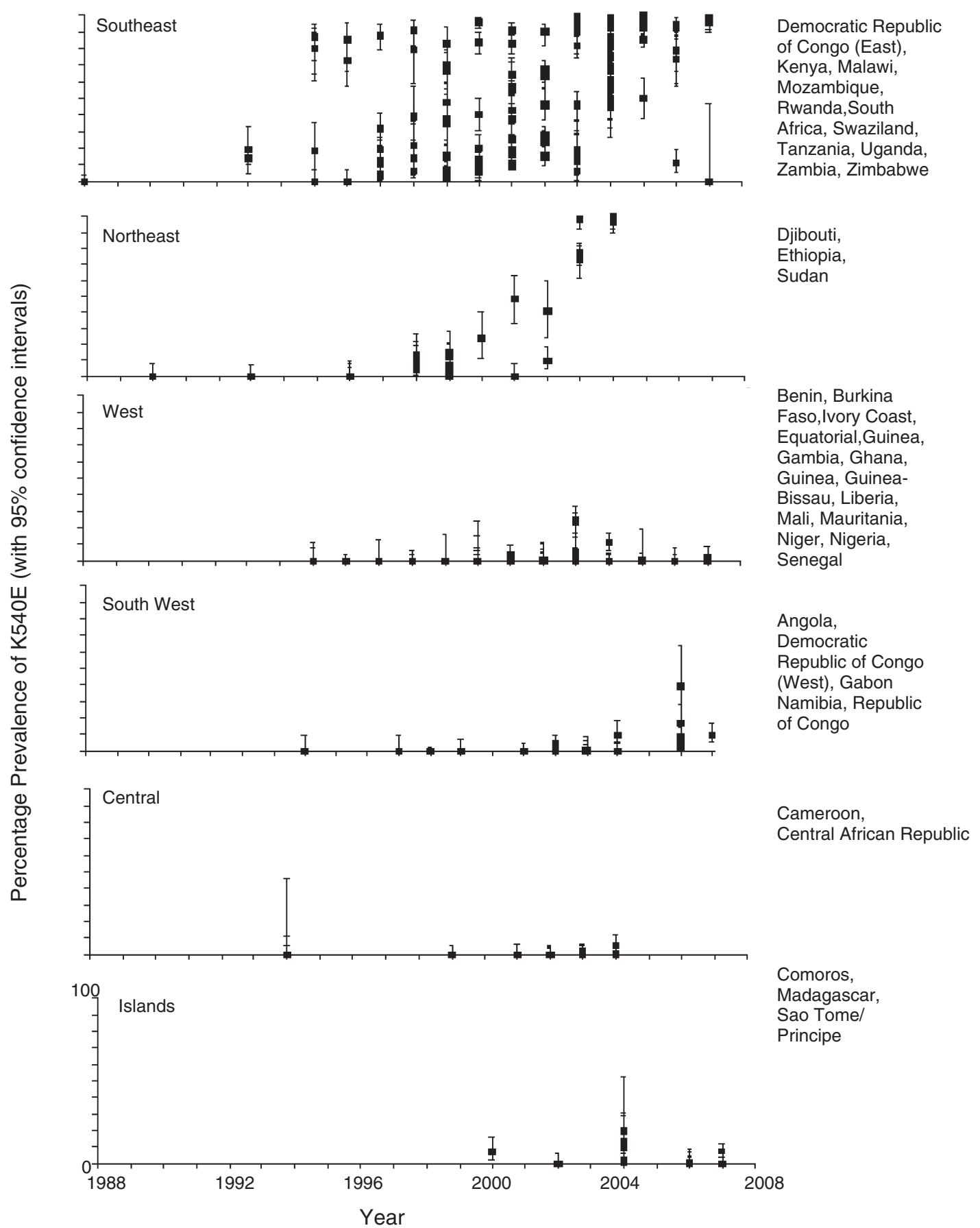

Fig. 1. Surveys of 540E prevalence (with 95\% confidence intervals) conducted during 1988-2008 and displayed according to their geographic region.

in southwest Uganda. At the more distant survey site at Mashesha (approximately $170 \mathrm{~km}$ from southwest Uganda) $d h f r 164 \mathrm{~L}$ was still absent but $d h p s 581$ was $30 \%$. The intensification of resistance in both sites predicts that SP efficacy will be exceptionally poor.

The collation of $540 \mathrm{E}$ data from seven recent surveys in five different sites in Tanzania indicated a range in prevalence from 50\% in 2005 in Chamwino to $97 \%$ in 2007 in Korogwe District (Enevold et al. 2007; Alifrangis et al. 2009). In Korogwe, Alifrangis et al. (2009) also reported $d h p s 581 \mathrm{G}$ at $12 \%$ but no $d h f r 164 \mathrm{~L}$ in surveys conducted between 2003 and 2007.

In Malawi, five surveys were conducted in 2005 and 2007 in four unique sites spanning the length of country. The prevalence of $540 \mathrm{E}$ reached extremes of 96\%-100\% (Bridges et al. 2009; Nkhoma et al. 2007). Additionally in 2003 , the prevalence of $581 \mathrm{G}$ was $3 \%$ and $164 \mathrm{~L}$ was $4 \%$ in Blantyre (Alker et al. 2005) although both these mutations remained absent in the other Malawian sites surveyed (Plowe et al. 1997; Bwijo et al. 2003; Bell et al. 2008; Bridges et al. 2009; Ochong et al. 2008). 


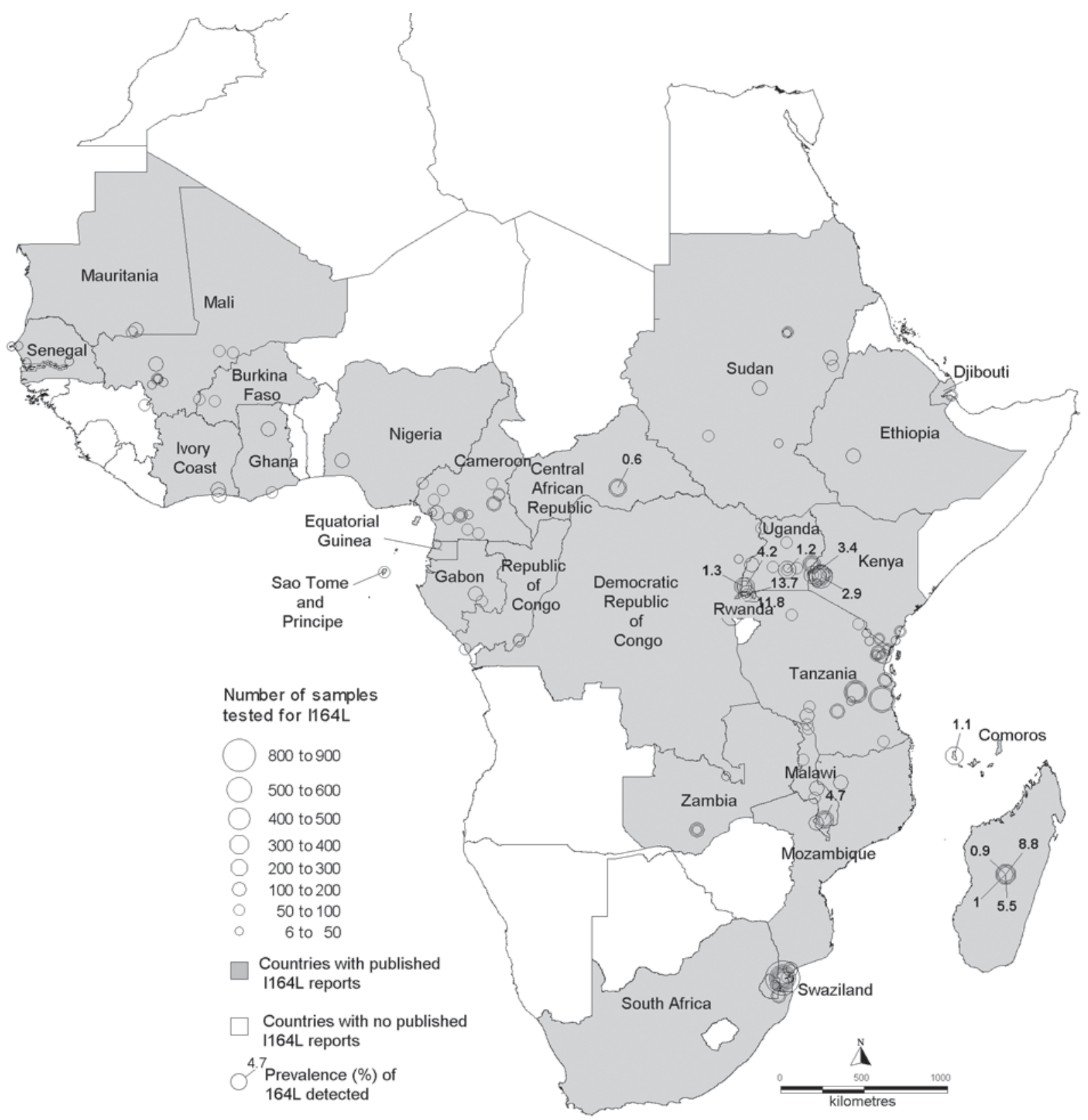

Fig 2. Map of $d h f r$ 164L survey sites. Countries where surveys were conducted are shaded and the survey sites are indicated by open circles. For positive surveys the prevalence of $164 \mathrm{~L}$ is indicated.

The picture in Zambia is mixed. Surveys in six Zambian sites during 2004 recorded 540E prevalences of between $46 \%-75 \%$ (Pearce et al. 2009) with just one survey at Mpongwe falling below the 50\% prevalence cut-off. However a survey in Macha in 2006 reported prevalence of 10\% 540E (Mkulama et al. 2008). No 164L was detected in Macha (Mkulama et al.2008) and there is no recent data on $581 \mathrm{G}$. These surveys indicate limited efficacy of SP in Zambia although additional monitoring of SP resistance genes including $581 \mathrm{G}$ are required.

In Mozambique, annual surveys between 2004 and 2008 at sentinel sites across Maputo district recorded the rise in prevalence of $540 \mathrm{E}$ across that region (Raman et al. 2010). Surveys in 2004 reported prevalences of $6 \%$ and $11 \%$. In 2005 this increased to $16 \%$ and in 2006 to $49 \%$. By 2008, prevalence exceeded $50 \%$ in all sentinel sites and the average prevalence across the region was $65 \%$. No $d h f r 164 \mathrm{~L}$ or dhps $581 \mathrm{G}$ was found in Maputo during 20042008 (Raman et al. 2010) and other studies found no $581 \mathrm{G}$ in other sites in Mozambique (Fernandes et al. 2007; Raman et al. 2008; Enosse et al. 2008). The resistant genotype is well established and surveillance at multiple sites confirms this to be highly consistent across a large geographical area.

In Madagascar, the dhps 540E was absent in 2006 (Andriantsoanirina et al. 2009) but an emerging focus of $164 \mathrm{~L}$ mutant alleles was reported in the south of the country in annual surveys conducted in 2006, 2007 and 2008. Uniquely in Africa, the Malagasy $164 \mathrm{~L}$ mutation is found as a single mutant and not in 


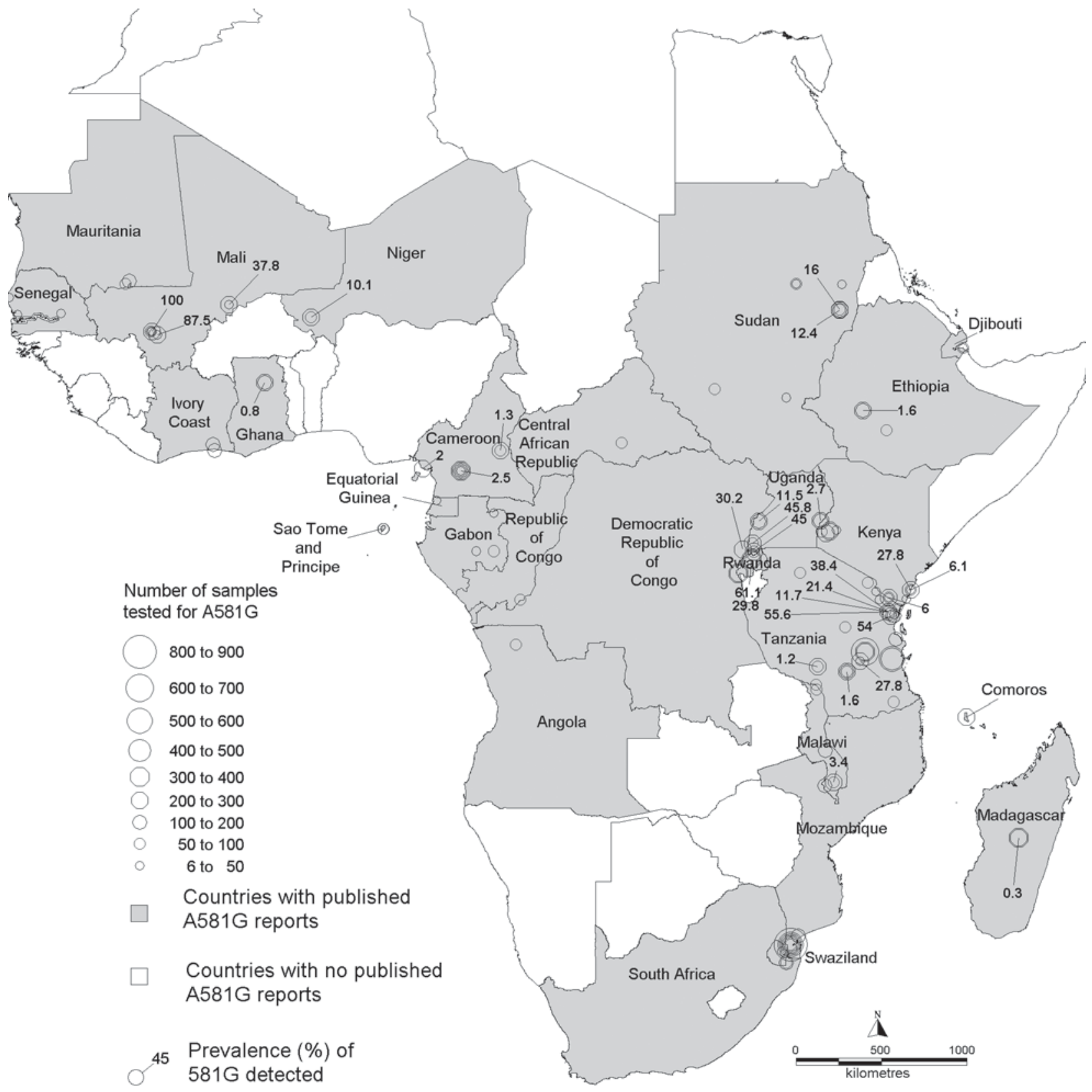

Fig 3. Map of $d h p s 581 \mathrm{G}$ survey sites. Countries where surveys were conducted are shaded and the survey sites are indicated by open circles. For positive surveys the prevalence of $581 \mathrm{G}$ is indicated.

combination with mutations at codons 51,59 or 108 . In vitro assays predict that the $164 \mathrm{~L}$ on its own will not confer significant resistance to pyrimethamine (Lozovsky et al. 2009). Based on the criteria of the $50 \% 540 \mathrm{E}$ prevalence threshold there should be no impediment to implimentation of SP-IPTi in Madagascar. However, given the unique combination of resistance mutations and the indications of their evolution in isolation from the mainland, it is recommended that local assessments of SP efficacy be conducted.

In Mali, there were reports of $d h p s 581 \mathrm{G}$, one from a survey in Bandiagara during 2000 (Thera et al. 2005) and another carried out prior to 1997 (Wang et al. 1997). The implications of this for efficacy of SP-IPTi are unknown and unfortunately recent surveys have not tested for $581 \mathrm{G}$ so the current situation with respect to this mutation in Mali is unknown. However the rarity of $540 \mathrm{E}$ in Mali was reconfirmed in recent large scale surveys ('Tekete et al. 2009, Djimde et al. 2008, Dicko et al. 2010).

\section{CONCLUSION}

High level SP resistance, as indicated by the prevalence of the $540 \mathrm{E}$ mutation, is advanced in sites all across East Africa. In Ethiopia, Kenya, Uganda, Rwanda, Tanzania, Malawi, Zambia and Mozambique measures of the prevalence of $540 \mathrm{E}$ were consistently $50 \%$ or higher since 2004 . In addition, there has been significant intensification of resistance in parts of Uganda and Rwanda through 


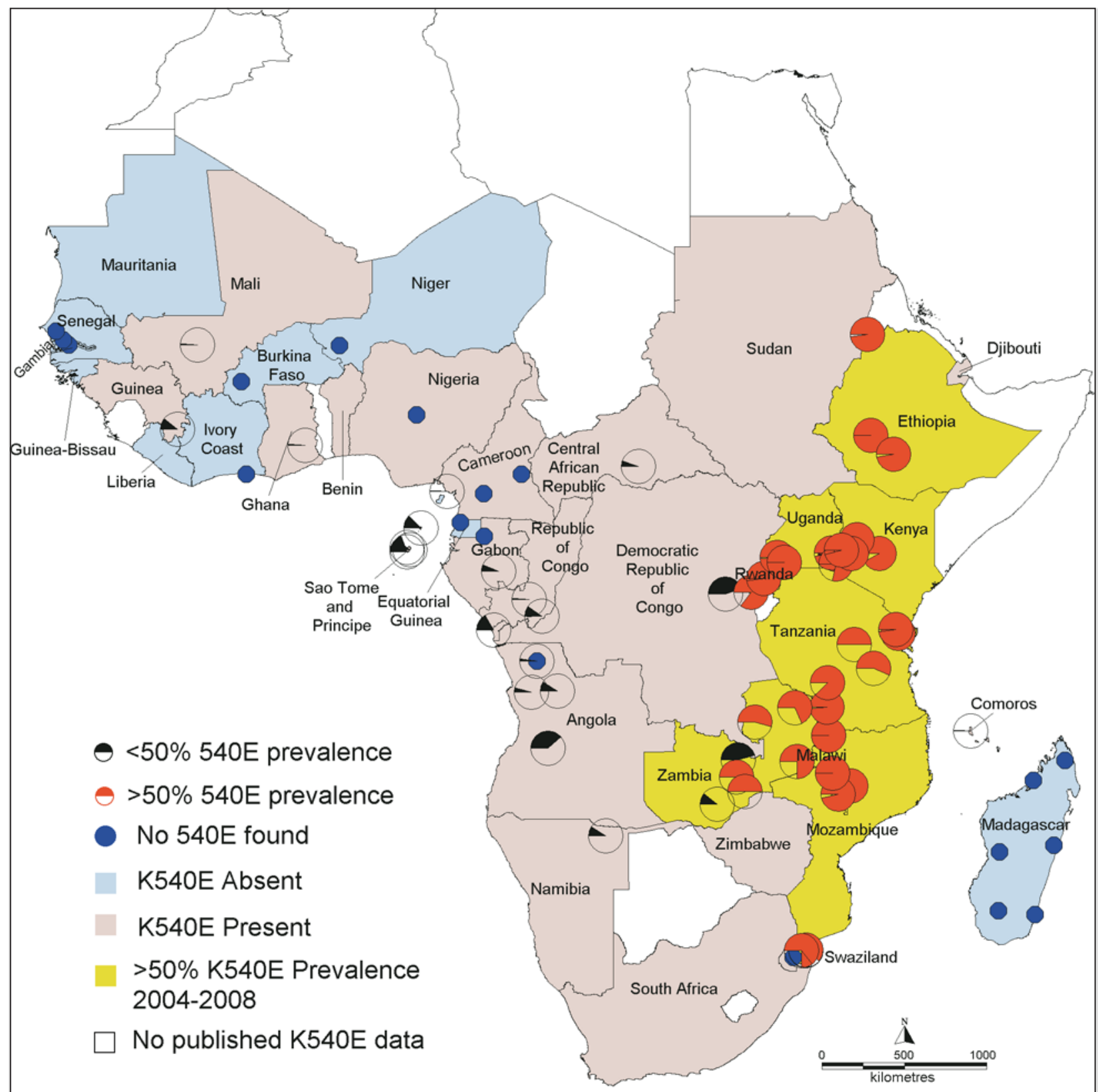

Fig 4. Map showing recent measures of the prevalence of 540E. All surveys conducted since 2004 are indicted by pie charts. The red pie charts indicate survey sites where prevalence exceeded $50 \%$ and these countries are shaded brown. The black pie charts indicate surveys with less than $50 \%$. Blue circles indicate zero prevalence $540 \mathrm{E}$. The countries shaded pink indicate that $540 \mathrm{E}$ has been detected at $<50 \%$ at some stage whereas the blue ones are where it has never been detected. White indicates countries where no data was available.

acquisition of $d h p s 581 \mathrm{G}$ and $d h f r 164 \mathrm{~L}$ mutations. In northern Tanzania there is a well established focus of $d h p s 581 \mathrm{G}$ although $164 \mathrm{~L}$ is absent. IPTi with SP is not recommended in these areas.

Elsewhere in Africa the $540 \mathrm{E}$ is encountered less frequently. Of the 36 countries for which data exists 27 have been confirmed to have $540 \mathrm{E}$ at low prevalence, leaving 10 countries: Burkina Faso, Gambia, Guinea-Bissau, Ivory Coast, Liberia, Madagascar, Mauritania, Niger, Senegal and Equatorial Guinea where recent surveys have been carried out but the $540 \mathrm{E}$ has still not been recorded.
Based on this, SP-IP'Ti, is still practicable throughout much of Africa.

It will be important to maintain surveillance for markers of SP resistance to monitor changes over the next few years. SP has been withdrawn as a treatment for clinical malaria and is now recommended solely for use in intermittent preventive treatment in pregnant women and infants With this policy change there is expected to be a significant reduction in drug pressure (Malisa et al. 2010). The cumulative reports of $540 \mathrm{E}$ so far have shown rising prevalence in East Africa and a gradual spread westward (Naidoo and 
Roper, 2010), it is likely these trends will slow or even discontinue now that SP drug pressure is reduced.

Surveillance in support of use of SP for IPTi or IPTp should be concentrated in areas where there is no data and those where resistance is currently borderline or heterogeneous. In the absence of local information the closest approximation is to look at resistance levels in sites in neighbouring states. For example, in Burundi it may be expected that high levels of SP resistance would occur because of measures made in neighbouring sites in Rwanda and Eastern Democratic Republic of Congo. In situations where resistance levels are borderline, such as the Democratic Republic of Congo and Sudan, it may be necessary to employ district level surveillance to inform IPTi policy at local administrative levels.

Supporting evidence of the region-wide circulation of drug resistance genotypes comes from molecular analysis of flanking microsatellite markers around dhps (Pearce et al. 2009) This study of resistant $d h p s$ alleles sampled in 20 African mainland countries showed that parasite populations are regional and probably are linked through networks of human circulation. Once a resistance mutation is established at a site it can rapidly be disseminated to other populations in the same regional genepool. Circulation of infected people between the major regions and between mainland and island populations is less frequent compared with their movement within regions and consequently exchange of resistance genes is more stochastic. Rogier (2005) reported that the Djibouti-Ethiopian railway was suspected to be an effective route for propagating malaria parasites. Both these countries lie in the Northeast region and it is expected (but as yet untested) that the SP resistance alleles will be common to both countries.

The importance of parasite circulation to shared resistance alleles among regional populations is an implicit assumption underlying the WHO recommendations. The presence of the dhps $540 \mathrm{E}$ is indicative of shared phenotype. In Madagascar, a picture of evolution of SP resistance determinants which was independent of the mainland emerged and a $164 \mathrm{~L}$ mutation was found in a novel haplotype not recorded in mainland Africa. This illustrates an important caution in the application of a simple threshold prevalence of the $540 \mathrm{E}$ mutation. On the mainland, it serves as a valuable approximation of resistance levels among populations which share common resistant alleles and in which efficacy in relation to those alleles is well understood. They are not informative in areas where background genetics of $d h f r$ and $d h p s$ are significantly different from areas where efficacy has been evaluated. In such cases, local evaluations of SP-IPTi efficacy are required.

Alternative treatments such as artemisinin-based combination therapies have not yet been sufficiently tested for safety, efficacy and interactions with the EPI to be advocated as alternatives to SP for IPTi. So use of IP'Ti rests upon the continuing efficacy of SP. Our recommendations for ongoing molecular surveillance of SP resistance markers in support of SP-IPTi policy in Africa are three fold. First, it is necessary that surveillance is introduced to the neglected geographical areas and coverage increased in countries like the Democratic Republic of Congo which have borderline levels of 540E. Secondly, ongoing molecular surveillance of $d h p s 540 \mathrm{E}$ should be maintained and expanded in sites throughout West and Central Africa in support of the continuing use of SP for intermittent preventive treatment there. Thirdly, monitoring of molecular markers in East Africa should be used to record the effect of reduction in drug pressure on the prevalence of SP resistance mutations.

\section{ACKNOWLEDGEMENTS}

We thank the database section of the Malaria Research Programme, Medical Research Council for support rendered.

\section{F INANCIAL SUPPORT}

The development of the drug resistance database was supported by funding from the Gates Malaria Partnership. The development of the website http://www.drugresistancemaps.org/ipti/ was funded by the IPTi consortium. Travel costs for CR to attend the special symposium on paediatric parasitology were paid by the BSP.

\section{REFERENCES}

Alifrangis, M., Lusingu, J.P., Mmbando, B., Dalgaard, M. B., Vestergaard, L.S., Ishengoma, D., Khalil, I. F., Theander, T. G., Lemnge, M. M. and Bygbjerg, I. C. (2009). Five-year surveillance of molecular markers of Plasmodium falciparum antimalarial drug resistance in Korogwe District, Tanzania: accumulation of the $581 \mathrm{G}$ mutation in the P. falciparum dihydropteroate synthase gene. American fournal of Tropical Medicine and Hygiene 80, 523-527.

Alker, A.P., Mwapasa, V., Purfield, A., Rogerson, S. J., Molyneux, M. E., Kamwendo, D. D., Tadesse, E., Chaluluka, E. and Meshnick, S. R. (2005). Mutations associated with sulfadoxine-pyrimethamine and chlorproguanil resistance in Plasmodium falciparum isolates from Blantyre, Malawi. Antimicrobial Agents and Chemotherapy 49, 3919-3921. Andriantsoanirina, V., Ratsimbasoa, A., Bouchier, C., Jahevitra, M., Rabearimanana, S., Radrianjafy, R., Andrianaranjaka, V., Randriantsoa, T., Rason, M. A., Tichit, M., Rabarijaona, L. P., Mercereau-Puijalon, O., Durand, R. and Menard, D. (2009). Plasmodium falciparum drug resistance in Madagascar: facing the spread of unusual pfdhfr and pfmdr-1 haplotypes and the decrease of dihydroartemisinin susceptibility. Antimicrobial Agents and Chemotherapy 53, 45884597.

Aponte, J.J., Schellenberg, D., Egan, A., Breckenridge, A., Carneiro, I., Critchley, J., Danquah, I., Dodoo, A., Kobbe, R., Lell, B., May, J., Premji, Z., Sanz, S., Sevene, E., SoulaymaniBecheikh, R., Winstanley, P., Adjei, S., Anemana, S., Chandramohan, D., Issifou, S., Mockenhaupt, F., Owusu-Agyei, S., Greenwood, B., Grobusch, M.P., Kremsner, P. G., Macete, E., Mshinda, H., Newman, R. D., Slutsker, L., Tanner, M., Alonso, P. and Menendez, C. (2009). Efficacy and safety of intermittent preventive treatment with sulfadoxine-pyrimethamine for malaria in African infants: a pooled analysis of six randomised, placebo-controlled trials. Lancet 374, 1533-1542. 
Bell, D. J., Nyirongo, S. K., Mukaka, M., Zijlstra, E. E., Plowe, C. V., Molyneux, M.E., Ward, S.A. and Winstanley, P.A. (2008) Sulfadoxine-pyrimethamine-based combinations for malaria: a randomised blinded trial to compare efficacy, safety and selection of resistance in Malawi. PLOS ONE 3, e1578.

Bonizzoni, M., Afrane, Y., Baliraine, F. N., Amenya, D. A. Githeko, A. K. and Yan, G. (2009). Genetic structure of Plasmodium falciparum populations between lowland and highland sites and antimalarial drug resistance in Western Kenya. Infection, Genetics and Evolution 9, 806-812.

Bridges, D. J., Molyneux, M. and Nkhoma, S. (2009). Low level genotypic chloroquine resistance near Malawi's northern border with Tanzania. Tropical Medicine and International Health 14, 1093-1096.

Brooks, D. R., Wang, P., Read, M., Watkins, W. M., Sims, P. F. and Hyde, J. E. (1994). Sequence variation of the hydroxymethyldihydropterin pyrophosphokinase: dihydropteroate synthase gene in lines of the human malaria parasite, Plasmodium falciparum, with differing resistance to sulfadoxine. European Fournal of Biochemistry 224, 397-405.

Bwijo, B., Kaneko, A., Takechi, M., Zungu, I. L., Moriyama, Y. Lum, J. K., Tsukahara, T., Mita, T., Takahashi, N., Bergqvist, Y., Bjorkman, A. and Kobayakawa, T. (2003). High prevalence of quintuple mutant dhps/dhfr genes in Plasmodium falciparum infections seven years after introduction of sulfadoxine and pyrimethamine as first line treatment in Malawi. Acta Tropica 85, 363-373.

Certain, L. K., Briceno, M., Kiara, S. M., Nzila, A. M., Watkins, W. M. and Sibley, C. H. (2008). Characteristics of Plasmodium falciparum $\mathrm{dhfr}$ haplotypes that confer pyrimethamine resistance, Kilifi, Kenya, 1987-2006. Fournal of Infectious diseases 197, 1743-1751.

Chandramohan, D., Owusu-Agyei, S., Carneiro, I., Awine, T., Amponsa-Achiano, K., Mensah, N., Jaffar, S., Baiden, R. Hodgson, A., Binka, F. and Greenwood, B. (2005). Cluster randomised trial of intermittent preventive treatment of malaria in infants in area of high, seasonal transmission in Ghana. British Medical Fournal 331, 727-733.

Cowman, A. F., Morry, M. J., Biggs, B. A., Cross, G. A. and Foote, S. J. (1988). Amino acid changes linked to pyrimethamine resistance in the dihydrofolate reductase-thymidylate synthase gene of Plasmodium falciparum. Proceedings of the National Academy of Sciences, USA 85, 9109-9113.

Dicko, A., Sagara, I., Djimde, A. A., Toure, S. O., Traore, M. Dama, S., Diallo, A. I., Barry, A., Dicko, M., Coulibaly, O.M., Rogier, C., De Sousa, A. and Doumbo, O. K. (2010). Molecular markers of resistance to sulphadoxine-pyrimethamine one year after implementation of intermittent preventive treatment of malaria in infants in Mali. Malaria Fournal 9,9 .

Djimde, A. A., Fofana, B., Sagara, I., Sidibe, B., Toure, S., Dembele, D., Dama, S., Ouologuem, D., Dicko, A. and Doumbo, O. K. (2008). Efficacy, safety, and selection of molecular markers of drug resistance by two ACTs in Mali. American fournal of Tropical Medicine and Hygiene 78, 455-461.

Dunyo, S., Ord, R., Hallett, R., Jawara, M., Walraven, G., Mesa, E. Coleman, R., Sowe, M., Alexander, N., Targett, G. A., Pinder, M. and Sutherland, C. J. (2006). Randomised trial of chloroquine/sulphadoxinepyrimethamine in Gambian children with malaria: impact against multidrug-resistant P. falciparum. PLoS Clinical Trials 1, e14.

Enevold, A., Nkya, W. M., Theisen, M., Vestergaard, L. S. Jensen, A. T., Staalsoe, T., Theander, T. G., Bygbjerg, I. C. and Alifrangis, M. (2007). Potential impact of host immunity on malaria treatment outcome in Tanzanian children infected with Plasmodium falciparum. Malaria fournal 6, 153.

Enosse, S., Magnussen, P., Abacassamo, F., Gomez-Olive, X. Ronn, A. M., Thompson, R. and Alifrangis, M. (2008). Rapid increase of Plasmodium falciparum $\mathrm{dhfr} / \mathrm{dhps}$ resistant haplotypes, after the adoption of sulphadoxine-pyrimethamine as first line treatment in 2002, in southern Mozambique. Malaria fournal 7, 115

Fernandes, N., Figueiredo, P., Do Rosario, V. E. and Cravo, P. (2007). Analysis of sulphadoxine/pyrimethamine resistance-conferring mutations of Plasmodium falciparum from Mozambique reveals the absence of the dihydrofolate reductase 164L mutant. Malaria fournal 6, 35.

Francis, D., Nsobya, S.L., Talisuna, A., Yeka, A., Kamya, M. R., Machekano, R., Dokomajilar, C., Rosenthal, P. J. and Dorsey, G. (2006). Geographic differences in antimalarial drug efficacy in Uganda are explained by differences in endemicity and not by known molecular markers of drug resistance. Fournal of Infectious Diseases 193, 978-986.

Gebru-Woldearegai, T., Hailu, A., Grobusch, M. P. and Kun, J. F. (2005). Molecular surveillance of mutations in dihydrofolate reductase and dihydropteroate synthase genes of Plasmodium falciparum in Ethiopia. American Fournal of Tropical Medicine and Hygiene 73, 1131-1134.

Gesase, S., Gosling, R.D., Hashim, R., Ord, R., Naidoo, I., Madebe, R., Mosha, J.F., Joho, A., Mandia, V., Mrema, H.,
Mapunda, E., Savael, Z., Lemnge, M., Mosha, F. W., Greenwood, B., Roper, C. and Chandramohan, D. (2009). High resistance of Plasmodium falciparum to sulphadoxine/pyrimethamine in northern Tanzania and the emergence of dhps resistance mutation at Codon 581. PLoS ONE 4, e4569.

Gosling, R. D., Gesase, S., Mosha, J. F., Carneiro, I., Hashim, R., Lemnge, M., Mosha, F. W., Greenwood, B. and Chandramohan, D. (2009). Protective efficacy and safety of three antimalarial regimens for intermittent preventive treatment for malaria in infants: a randomised, double-blind, placebo-controlled trial. Lancet 374, 1521-1532.

Griffin, J. T., Cairns, M., Ghani, A. C., Roper, C., Schellenberg, D., Carneiro, I., Newman, R. D., Grobusch, M.P., Greenwood, B., Chandramohan, D. and Gosling, R. D. (2010). Protective efficacy of intermittent preventive treatment of malaria in infants (IPTi) using sulfadoxine-pyrimethamine and parasite resistance. PLoS ONE 5, e12618. Grobusch, M. P., Egan, A., Gosling, R. D. and Newman, R. D. (2007a) Intermittent preventive therapy for malaria: progress and future directions. Current Opinion in Infectious Diseases 20, 613-620.

Grobusch, M. P., Lell, B., Schwarz, N. G., Gabor, J., Dornemann, J. Potschke, M., Oyakhirome, S., Kiessling, G. C., Necek, M., Langin, M. U., Klein Klouwenberg, P., Klopfer, A., Naumann, B., Altun, H., Agnandji, S. T., Goesch, J., Decker, M., Salazar, C. L., Supan, C., Kombila, D. U., Borchert, L., Koster, K. B., Pongratz, P., Adegnika, A. A., Glasenapp, I., Issifou, S. and Kremsner, P. G. (2007b). Intermittent preventive treatment against malaria in infants in Gabon-a randomized, double-blind, placebo-controlled trial. Fournal of Infectious diseases 196, 1595-1602.

Harrington, W.E., Mutabingwa, T.K., Muehlenbachs, A., Sorensen, B., Bolla, M. C., Fried, M. and Duffy, P.E. (2009) Competitive facilitation of drug-resistant Plasmodium falciparum malaria parasites in pregnant women who receive preventive treatment. Proceedings of the National Academy, USA 106, 9027-9032.

Karema, C., Imwong, M., Fanello, C. I., Stepniewska, K., Uwimana, A., Nakeesathit, S., Dondorp, A., Day, N.P. and White, N. J. (2010). Molecular correlates of high level antifolate resistance in Rwandan children with Plasmodium falciparum malaria. Antimicrobial Agents and Chemotherapy 54, 477-483.

Kobbe, R., Kreuzberg, C., Adjei, S., Thompson, B., Langefeld, I., Thompson, P. A., Abruquah, H. H., Kreuels, B., Ayim, M., Busch, W., Marks, F., Amoah, K., Opoku, E., Meyer, C. G., Adjei, O. and May, J. (2007). A randomized controlled trial of extended intermittent preventive antimalarial treatment in infants. Clinical Infectious Diseases $\mathbf{4 5}$, $16-25$.

Kublin, J. G., Dzinjalamala, F. K., Kamwendo, D. D., Malkin, E. M., Cortese, J.F., Martino, L. M., Mukadam, R. A., Rogerson, S. J., Lescano, A. G., Molyneux, M. E., Winstanley, P. A., Chimpeni, P., Taylor, T.E. and Plowe, C. V. (2002). Molecular markers for failure of sulfadoxine-pyrimethamine and chlorproguanil-dapsone treatment of Plasmodium falciparum malaria. Fournal of Infectious Diseases 185, 380-388. Kun, J. F., Lehman, L. G., Lell, B., Schmidt-Ott, R. and Kremsner, P. G. (1999). Low-dose treatment with sulfadoxine-pyrimethamine combinations selects for drug-resistant Plasmodium falciparum strains. Antimicrobial Agents and Chemotherapy 43, 2205-2208.

Lozovsky, E. R., Chookajorn, T., Brown, K. M., Imwong, M. Shaw, P.J., Kamchonwongpaisan, S., Neafsey, D. E., Weinreich, D. M. and Hartl, D. L. (2009). Stepwise acquisition of pyrimethamine resistance in the malaria parasite. Proceedings of the National Academy of Sciences, USA 106, 12025-12030.

Lynch, C., Pearce, R., Pota, H., Cox, J., Abeku, T. A., Rwakimari, J., Naidoo, I., Tibenderana, J. and Roper, C. (2008). Emergence of a dhfr mutation conferring high-level drug resistance in Plasmodium falciparum populations from southwest Uganda. Fournal of Infectious Diseases 197, 1598-1604

Macete, E., Aide, P., Aponte, J. J., Sanz, S., Mandomando, I., Espasa, M., Sigauque, B., Dobano, C., Mabunda, S., Dgedge, M. Alonso, P. and Menendez, C. (2006). Intermittent preventive treatment for malaria control administered at the time of routine vaccinations in Mozambican infants: a randomized, placebo-controlled trial. Fournal of Infectious Diseases 194, 276-285.

Maiga, O., Djimde, A. A., Hubert, V., Renard, E., Aubouy, A. Kironde, F., Nsimba, B., Koram, K., Doumbo, O. K., Le Bras, J. and Clain, J. (2007). A shared Asian origin of the triple-mutant dhfr allele in Plasmodium falciparum from sites across Africa. Fournal of Infectious Diseases 196, 165-172.

Malisa, A. L., Pearce, R. J., Abdulla, S., Mshinda, H., Kachur, P.S., Bloland, P. and Roper, C. (2010). Drug coverage in treatment of malaria and the consequences for resistance evolution-evidence from the use of sulphadoxine/pyrimethamine. Malaria Fournal 9, 190 
Marks, F., Evans, J., Meyer, C. G., Browne, E. N., Flessner, C., Von Kalckreuth, V., Eggelte, T. A., Horstmann, R. D. and May, J. (2005). High prevalence of markers for sulfadoxine and pyrimethamine resistance in Plasmodium falciparum in the absence of drug pressure in the Ashanti region of Ghana. Antimicrobial Agents and Chemotherapy 49, 1101-1105.

McCollum, A. M., Poe, A.C., Hamel, M., Huber, C., Zhou, Z., Shi, Y.P., Ouma, P., Vulule, J., Bloland, P., Slutsker, L., Barnwell, J. W., Udhayakumar, V. and Escalante, A. A. (2006). Antifolate resistance in Plasmodium falciparum: multiple origins and identification of novel dhfr alleles. Fournal of Infectious Diseases 194, 189-197.

Menegon, M., Pearce, R. J., Inojosa, W. O., Pisani, V., Abel, P. M., Matondo, A., Bisoffi, Z., Majori, G., Ord, R., Warhurst, D. C., Roper, C. and Severini, C. (2009). Monitoring for multidrug-resistant Plasmodium falciparum isolates and analysis of pyrimethamine resistance evolution in Uige province, Angola. Tropical Medicine and International Health 14, 1251-1257

Mkulama, M. A., Chishimba, S., Sikalima, J., Rouse, P., Thuma, P. E. and Mharakurwa, S. (2008). Escalating Plasmodium falciparum antifolate drug resistance mutations in Macha, rural Zambia. Malaria fournal 7, 87. Mockenhaupt, F. P., Reither, K., Zanger, P., Roepcke, F., Danquah, I., Saad, E., Ziniel, P., Dzisi, S. Y., Frempong, M., Agana-Nsiire, P., Amoo-Sakyi, F., Otchwemah, R., Cramer, J.P., Anemana, S. D., Dietz, E. and Bienzle, U. (2007). Intermittent preventive treatment in infants as a means of malaria control: a randomized, double-blind, placebocontrolled trial in northern Ghana. Antimicrobial Agents and Chemotherapy 51, 3273-3281.

Mockenhaupt, F. P., Teun Bousema, J., Eggelte, T. A., Schreiber, J., Ehrhardt, S., Wassilew, N., Otchwemah, R. N., Sauerwein, R. W. and Bienzle, U. (2005). Plasmodium falciparum dhfr but not dhps mutations associated with sulphadoxine-pyrimethamine treatment failure and gametocyte carriage in northern Ghana. Tropical Medicine and International Health 10, 901-908.

Naidoo, I. and Roper, C. (2010). Following the path of most resistance: dhps K540E dispersal in African Plasmodium falciparum. Trends in Parasitology 26, 447-456.

Ndounga, M., Tahar, R., Basco, L. K., Casimiro, P. N., Malonga, D. A. and Ntoumi, F. (2007). Therapeutic efficacy of sulfadoxine-pyrimethamine and the prevalence of molecular markers of resistance in under 5-year olds in Brazzaville, Congo. Tropical Medicine and International Health 12, 1164-1171

Nkhoma, S., Molyneux, M. and Ward, S. (2007). Molecular surveillance for drug-resistant Plasmodium falciparum malaria in Malawi. Acta Tropica 102, 138-142.

Ochong, E., Bell, D. J., Johnson, D. J., D’alessandro, U., Mulenga, M., Muangnoicharoen, S., Van Geertruyden, J.P., Winstanley, P. A., Bray, P. G., Ward, S. A. and Owen, A. (2008). Plasmodium falciparum strains harboring dihydrofolate reductase with the $\mathrm{I} 164 \mathrm{~L}$ mutation are absent in Malawi and Zambia even under antifolate drug pressure. Antimicrobial Agents and Chemotherapy 52, 3883-3888.

Omar, S. A., Adagu, I. S. and Warhurst, D. C. (2001). Can pretreatment screening for dhps and dhfr point mutations in Plasmodium falciparum infections be used to predict sulfadoxine-pyrimethamine treatment failure? Transactions of the Royal Society of Tropical Medicine and Hygiene 95, 315-319

Pearce, R. J., Pota, H., Evehe, M.S., Ba El, H., Mombo-Ngoma, G., Malisa, A. L., Ord, R., Inojosa, W., Matondo, A., Diallo, D. A., Mbacham, W., Van Den Broek, I.V., Swarthout, T.D., Getachew, A., Dejene, S., Grobusch, M.P., Njie, F., Dunyo, S., Kweku, M., Owusu-Agyei, S., Chandramohan, D., Bonnet, M., Guthmann, J. P., Clarke, S., Barnes, K. I., Streat, E., Katokele, S. T., Uusiku, P., Agboghoroma, C. O., Elegba, O. Y., Cisse, B., Ie, A. E., Giha, H. A., Kachur, S. P., Lynch, C., Rwakimari, J. B., Chanda, P., Hawela, M., Sharp, B., Naidoo, I. and Roper, C. (2009). Multiple origins and regional dispersal of resistant dhps in African Plasmodium falciparum malaria. PLoS Medicine 6, e1000055.

Peterson, D. S., Walliker, D. and Wellems, T. E. (1988). Evidence that a point mutation in dihydrofolate reductase-thymidylate synthase confers resistance to pyrimethamine in falciparum malaria. Proceedings of the National Academy of Sciences, USA 85, 9114-9118.

Plowe, C.V., Cortese, J.F., Djimde, A., Nwanyanwu, O.C., Watkins, W. M., Winstanley, P.A., Estrada-Franco, J. G.,
Mollinedo, R. E., Avila, J. C., Cespedes, J. L., Carter, D. and Doumbo, O. K. (1997). Mutations in Plasmodium falciparum dihydrofolate reductase and dihydropteroate synthase and epidemiologic patterns of pyrimethamine-sulfadoxine use and resistance. Fournal of Infectious diseases 176, 1590-1596.

Raman, J., Little, F., Roper, C., Kleinschmidt, I., Cassam, Y., Maharaj, R. and Barnes, K. I. (2010). Five years of large-scale dhfr and dhps mutation surveillance following the phased implementation of artesunate plus sulfadoxine-pyrimethamine in Maputo Province, Southern Mozambique. American Fournal of Tropical Medicine and Hygiene 82, 788-794.

Raman, J., Sharp, B., Kleinschmidt, I., Roper, C., Streat, E., Kelly, V. and Barnes, K. I. (2008). Differential effect of regional drug pressure on dihydrofolate reductase and dihydropteroate synthetase mutations in southern Mozambique. American Fournal of Tropical Medicine and Hygiene 78, 256-261.

Rogier, C., Pradines, B., Bogreau, H., Koeck, J. L., Kamil, M. A. and Mercereau-Puijalon, O. (2005). Malaria epidemic and drug resistance, Djibouti. Emerging Infectious Diseases 11, 317-321.

Roper, C., Pearce, R., Nair, S., Sharp, B., Nosten, F. and Anderson, T. (2004). Intercontinental spread of pyrimethamine-resistant malaria. Science 305,1124

Schellenberg, D., Menendez, C., Aponte, J.J., Kahigwa, E., Tanner, M., Mshinda, H. and Alonso, P. (2005). Intermittent preventive antimalarial treatment for Tanzanian infants: follow-up to age 2 years of a randomised, placebo-controlled trial. Lancet 365, 1481-1483.

Schellenberg, D., Menendez, C., Kahigwa, E., Aponte, J., Vidal, J., Tanner, M., Mshinda, H. and Alonso, P. (2001). Intermittent treatment for malaria and anaemia control at time of routine vaccinations in Tanzanian infants: a randomised, placebo-controlled trial. Lancet $\mathbf{3 5 7}$, 1471-1477.

Schunk, M., Kumma, W. P., Miranda, I. B., Osman, M. E., Roewer, S., Alano, A., Loscher, T., Bienzle, U. and Mockenhaupt, F. P. (2006) High prevalence of drug-resistance mutations in Plasmodium falciparum and Plasmodium vivax in southern Ethiopia. In Malaria Fournal 5, 54.

Staedke, S. G., Sendagire, H., Lamola, S., Kamya, M. R., Dorsey, G. and Rosenthal, P. J. (2004). Relationship between age, molecular markers, and response to sulphadoxine-pyrimethamine treatment in Kampala, Uganda. Tropical Medicine and International Health 9, 624-629.

Tekete, M., Djimde, A. A., Beavogui, A. H., Maiga, H., Sagara, I., Fofana, B., Ouologuem, D., Dama, S., Kone, A., Dembele, D. Wele, M., Dicko, A. and Doumbo, O. K. (2009). Efficacy of chloroquine, amodiaquine and sulphadoxine-pyrimethamine for the treatment of uncomplicated falciparum malaria: revisiting molecular markers in an area of emerging AQ and SP resistance in Mali. Malaria fournal 8, 34

Thera, M. A., Sehdev, P. S., Coulibaly, D., Traore, K., Garba, M. N. Cissoko, Y., Kone, A., Guindo, A., Dicko, A., Beavogui, A. H., Diimde, A.A., Lyke, K.E., Diallo, D.A., Doumbo, O.K. and Plowe, C. V. (2005). Impact of trimethoprim-sulfamethoxazole prophylaxis on falciparum malaria infection and disease. Fournal of Infectious Diseases 192, 1823-1829.

Triglia, T. and Cowman, A. F. (1994). Primary structure and expression of the dihydropteroate synthetase gene of Plasmodium falciparum. Proceedings of the National Academy of Sciences, USA 91, 7149-7153.

Triglia, T., Menting, J. G., Wilson, C. and Cowman, A. F. (1997). Mutations in dihydropteroate synthase are responsible for sulfone and sulfonamide resistance in Plasmodium falciparum. Proceedings of the National Academy of Sciences, USA 94, 13944-13949.

Wang, P., Lee, C.S., Bayoumi, R., Djimde, A., Doumbo, O., Swedberg, G., Dao, L.D., Mshinda, H., Tanner, M., Watkins, W. M., Sims, P.F. and Hyde, J.E. (1997). Resistance to antifolates in Plasmodium falciparum monitored by sequence analysis of dihydropteroate synthetase and dihydrofolate reductase alleles in a large number of field samples of diverse origins. Molecular and Biochemical Parasitology 89, 161-177.

WHO (2009). Technical Consultation on Intermittent Preventive Treatment in Infants (IPTi), Technical Expert Group on Preventive Chemotherapy.WHO TEG IPTi Report April 2009. World Health Organisation pp. 1-11.

Zhong, D., Afrane, Y., Githeko, A., Cui, L., Menge, D. M. and Yan, G. (2008). Molecular epidemiology of drug-resistant malaria in western Kenya highlands. In BMC Infectious Diseases 8, 105. 